\title{
Impact of Socioeconomic and Social Contexts on Youth Perceptions of School Nutrition Policy Development in Lebanon
}

\author{
Hamadeh $\mathrm{S}^{* 1}$ and Marquis $\mathrm{M}^{2}$ \\ ${ }^{1}$ Department of Nutrition and Dietetics Sciences, Faculty of Arts and Sciences, Haigazian University, Lebanon \\ ${ }^{2}$ Department of Nutrition, Faculty of Medicine, University of Montreal, Canada
}

${ }^{*}$ Corresponding author: Sima Hamadeh, Department of Nutrition and Dietetics Sciences, Faculty of Arts and Sciences, Haigazian University, Lebanon, E-mail address: sima.hamadeh@haigazian.edu.lb

Citation: Hamadeh S, Marquis M (2017) Impact of Socioeconomic and Social Contexts on Youth Perceptions of School Nutrition Policy Development in Lebanon. J Nutr Health Sci 4(1): 101. doi: 10.15744/2393-9060.4.101

Received Date: November 28, 2016 Accepted Date: February 10, 2017 Published Date: May 03, 2017

\begin{abstract}
School represents a proper place for health promotion among youth. This study aimed to explore the determinants of an eventual school nutrition policy (SNP) development by studying the perceptions of youth coming from different social contexts in Lebanon. It was a qualitative study conducted among 48 children and adolescents aged between 10 and 14 years in 8 schools ( 4 private and 4 public) in rural and urban Lebanese regions. An exhaustive integrated conceptual framework was used to explore the perceived determinants at different levels of action, namely individual, community/interpersonal and organizational. Directed and semi-structured individual interviews were conducted with youth. Data from this research have been submitted to a thematic qualitative analysis to identify barriers and facilitators of SNP development in Lebanon. Coding guide was based on the integrated comprehensive conceptual framework. Transcripts were coded and revised by the 2 researchers for common themes.

The results showed that an understanding of how the individual, community and organizational factors interact and influence youth lifestyle and perceptions is crucial to develop an effective SNP. Characteristics of the Lebanese social environment, including various socioeconomic and cultural factors such as beliefs, socioeconomic status, food-related social pressures, and social structures are major determinants of SNP development in different school profiles. It is important to integrate a comprehensive approach to explore youth perceptions of barriers and facilitators at different levels of influence, which complement and build upon each other, in order to thrive SNP development.
\end{abstract}

Keywords: Nutrition school policy; Physical Activity; Youth perceptions; Health Promotion; Nutrition economics

\section{Introduction}

As obesity has come to the forefront of public health concerns, there is growing interest in finding ways to guide consumers' food choices to be more beneficial for their long-term health [1-3]. The recent emerging of nutrition economics discipline is crucial to increase the understanding of nutrition's impact on disease prevention $[4,5]$ and to generate nutrition policy relevant evidence [6]. The nutrition economic analysis is used to evaluate if and how much healthy lifestyle choices will vary with 3 primary economic variables: income, food prices, and information about nutrition and health [4]. This analysis can help explain some of the reasons behind lifestyle choices but its impact is limited. Thus, there is a need to add more realism into economic analysis by incorporating the sociological, psychological, physiological and behavioral aspects of dietary and physical activity patterns [4,7]. Such a comprehensive approach reveals a broader range of policy options to increase the likelihood that individuals will have better lifestyles and helps nutritionists, economists and policymakers better understand food choices $[3,4,8,9]$.

Currently in most of the world, youth food consumption, physical activity and leisure time activities trends show a shift over the past few decades towards unhealthy patterns $[1,10,11]$. These recent trends could carry important immediate and longerterm developmental and health risks such as obesity, type 2 diabetes, CVD, some types of cancer in addition to psychological disturbances $[6,9,10,12]$. Improving diet quality among youth has the potential to guide food choices at a critical time, when a person's dietary preferences are being defined, and to impact individual and societal economics [1,5].

Environmental influences including communities-based institutions (schools, food stores, restaurants) and peers are perceived to be the greatest on youth lifestyle, especially adolescents and conflict with parental influences leading to an assertion of individual personality and choice $[8,9,13]$. Researchers have begun to focus on family and social influences on youth lifestyle patterns $[14,15]$. Schools and families could indeed contribute to help youth become "health literate" and learn skills to identify, analyze, investigate 
and refute what is being portrayed about nutrition and healthy lifestyle in media, advertising neighborhood and society $[9,11,15-$ 17].

During the past few years, Lebanon has been experiencing a nutritional transition in food and lifestyle patterns [18]. A distinctive feature of the nutrition transition, especially among youth, is the shift toward an energy dense dietary patterns and the adoption of sedentary lifestyle [13]. Thus, overweight and obesity are increasingly being observed among the youth, especially among boys $[1,19,20]$. In 2009, the World Health Organization (WHO), the Ministry of Health, the Ministry of Education and the School national committee of Health in Lebanon proposed the "Strategy of school health" (SSH) to improve the health condition of the students, the school personnel and the communities [21]. To the best of our knowledge, no previous official strategies had supported the implementation of the nutrition component of the SSH. Thus, it is important to understand how the youth perceive the elements of this strategy before developing a school nutrition policy (SNP). The aim of this study is to explore the determinants of an eventual SNP development by studying the perceptions of youth coming from different social contexts in Lebanon. Could similar approaches be used in different school profiles to improve diet quality and promote physical activity among Lebanese youth?

\section{Materials and methods}

The sample of this study $(\mathrm{n}=48)$ was stratified in 2 geographical areas in Lebanon including the capital Beirut "urban region" and the Mount Lebanon "rural area". A total of 8 schools (2 public rural, 2 public urban, 2 private rural and 2 private urban) composed this sample. All schools offer education in primary and complementary cycles, therefore serving young people aged between 10 and 14 years. In each school, 6 youth ( 3 children "10-11 years" and 3 adolescents "12-14 years") were recruited.

\section{Research Design}

Several studies suggest mixing theories and models within the social marketing approach in health promotion programs [22,2325]. In this study, an integrating comprehensive conceptual framework (Figure 1) is proposed with an aim of understanding the determinants of SNP in Lebanon. This conceptual framework results from using several theories and models based on social marketing to explore the perceived determinants at various levels of action including individual, community/interpersonal and organizational levels [26]. The theories and models used are the Theory of Trying, the Rossister-Percy Motivational Model, the Health Belief Model, the Protection Motivation Theory, the Diffusion Theory, the Theories of Organizational Change, and the Communication Theory [26]. The value of this theoretical combination is to highlight the complexity of the variables to be considered in order to ensure the success of an eventual SNP [23-25]. Further research describes the pertinence of using these appropriate theories and model within a social marketing approach to guide interviews with adults and youth as a prelude to SNP development [Hamadeh \& Marquis, accepted by IJNFC 2016].

\section{Instrumentation and Measures}

The first author of this study conducted directed and semi-structured individual interviews with students for a maximum duration of 30 minutes. The profile of the school (factual description, socio-economic profile of students, external and internal food school environment) was obtained from the schools' principals to define the school environment.

Students were asked to answer different questions related to the variables of the integrated conceptual framework of this study. Psychosocial and demographic questions were used to estimate their weight, height, social structure, sports and leisure time activities preferences, and food habits. Based on auto-reported age, weight and height, body mass index was calculated [27].

The questionnaire was prepared in three languages (English, French and Arabic) to reach all the participants accordingly to their language skills. The validity of the integrated conceptual framework and its variables used in the interview questionnaire was assessed with an external panel of experts in Quebec involved in the field of health promotion policies especially in schools. Their evaluation confirmed the adequacy of the scientific and theoretical content of this study to develop an effective data collection and feedback system (questionnaire) for an eventual SNP deployment.

\section{Data collection}

The study was carried out between September 2010 and February 2011. On acceptance of this project, the school principals have been invited to identify potential students from both genders aged between 10 to 14 years old and able to articulate their perceptions. Parental consent included opt-out forms were sent home with each student. Although the data were anonymous, a registration number was available for all students to ensure there was no duplication. The research study was approved by the ethics committee of the Faculty of medicine at the University of Montreal.

\section{Data Analysis}

Data from this formative research have been submitted to a thematic qualitative analysis [28]. All interviews were audiotaped, transcribed verbatim, reviewed and coded by researchers. 


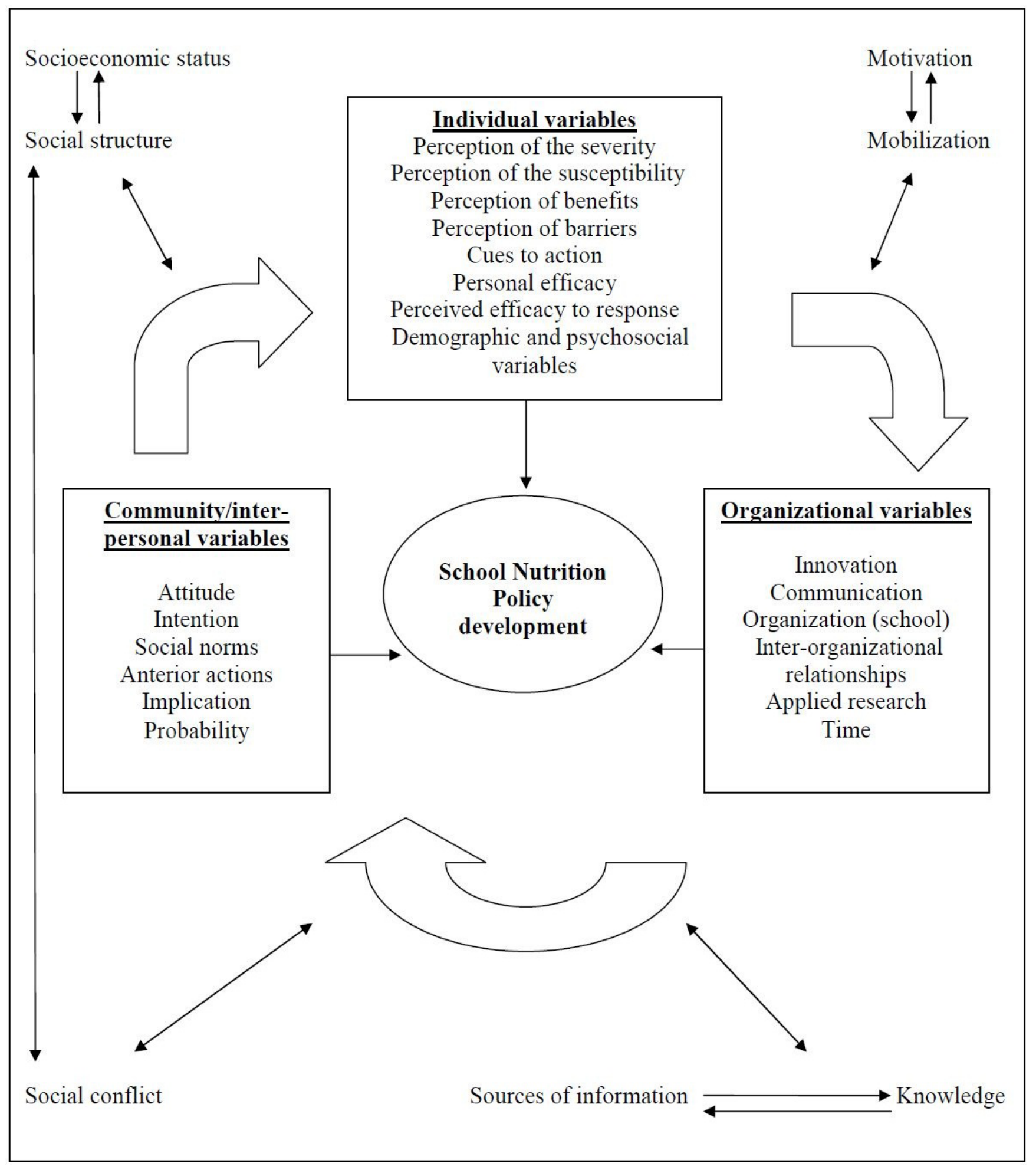

Figure 1: Integrated conceptual framework to study youth perceptions associated to an eventual School Nutrition Policy (SNP) development in Lebanon

The first stage of the data analysis involved the production of major findings for each interview. They were then grouped and reduced into common themes under the categories of variables (individual, community, organizational, etc.) of the conceptual framework according to the geographic areas (urban, rural) and the school profile (private, public). The synthesis was iterative. Whenever new themes emerged, they were retained and considered as facilitating factors or barriers to SNP deployment.

\section{Results}

\section{Respondents' Profile}

A total of 48 youth (20 boys and 28 girls) aged between 10 and 14 years participated in this study coming from different socioeconomic levels and social contexts. Body Mass Index calculated from self-reported showed that weight problems, especially 
underweight and overweight, are more common in rural private and urban schools respectively. Table 1 outlines the baseline characteristics of students from different schools profile and social contexts.

\begin{tabular}{|c|c|c|c|c|c|c|}
\hline \multirow{2}{*}{\multicolumn{2}{|c|}{$\begin{array}{l}\text { Schools profile } \\
\begin{array}{l}\text { Sample } \\
\text { characteristics }\end{array} \\
\end{array}$}} & \multicolumn{2}{|c|}{ Urban } & \multicolumn{2}{|c|}{ Rural } & \multirow{2}{*}{$\begin{array}{l}\text { Total (N) } \\
\text { (From } 8 \\
\text { schools) }\end{array}$} \\
\hline & & 2 private & 2 public & 2 private & 2 public & \\
\hline \multicolumn{2}{|c|}{ Boys (n) } & 6 & 6 & 4 & 4 & 20 \\
\hline \multirow{5}{*}{ Age (years) } & $10 y$ & 0 & 0 & 1 & 1 & 2 \\
\hline & $11 \mathrm{y}$ & 1 & 2 & 0 & 3 & 6 \\
\hline & $12 y$ & 3 & 1 & 2 & 0 & 6 \\
\hline & $13 y$ & 1 & 2 & 0 & 0 & 3 \\
\hline & $14 \mathrm{y}$ & 1 & 1 & 1 & 0 & 3 \\
\hline \multirow{4}{*}{ BMI } & Underweight & 1 & 1 & 2 & 1 & 5 \\
\hline & Normal weight & 4 & 4 & 2 & 2 & 12 \\
\hline & Overweight & 0 & 1 & 0 & 1 & 2 \\
\hline & Obese & 1 & 0 & 0 & 0 & 1 \\
\hline \multicolumn{2}{|c|}{ Girls (n) } & 6 & 6 & 8 & 8 & 28 \\
\hline \multirow{5}{*}{$\begin{array}{c}\text { Age } \\
\text { (years) }\end{array}$} & $10 y$ & 0 & 1 & 0 & 1 & 2 \\
\hline & $11 y$ & 1 & 0 & 3 & 0 & 4 \\
\hline & $12 y$ & 1 & 2 & 0 & 1 & 4 \\
\hline & $13 y$ & 3 & 1 & 4 & 3 & 11 \\
\hline & $14 y$ & 1 & 2 & 1 & 3 & 7 \\
\hline \multirow{4}{*}{ BMI } & Underweight & 1 & 1 & 3 & 1 & 6 \\
\hline & Normal weight & 4 & 5 & 5 & 7 & 21 \\
\hline & Overweight & 1 & 0 & 0 & 0 & 1 \\
\hline & Obese & 0 & 0 & 0 & 0 & 0 \\
\hline \multicolumn{2}{|c|}{ Total (N) } & 12 & 12 & 12 & 12 & 48 \\
\hline
\end{tabular}

Table 1: Characteristics of Youth Participants from Different Schools Profile (N=48)

\section{School Context in Lebanon}

The Lebanese school context is very heterogeneous. There are cultural, economic and religious disparities between private and public schools. Students attending private schools, especially urban private schools, are wealthier and belong to affluent social contexts than students attending public schools.

School food services are supervised by teachers trained to be health advisors in public schools and by school administration in private schools. However, the type of food service varies from schools to another. In rural areas, food services consist of kiosks sponsored by soft drinks companies and usually offer soft drinks and unhealthy snacks. In urban areas, food services in public schools are kiosks while those of private schools are cafeterias or canteens with cycle traditional food menus. Vending machines are banned in all schools.

Physical activity is a major concern for private schools, which assign 2 to 4 hours per week. School extra-curriculum activities are common only in private schools and include sports events for students and teachers. Only private schools have an appropriate built environment (seasonal play yards, well equipped classrooms, libraries, health care services and food services), and responsible staff (director, teachers, food service manager) building relationships of mutual respect with students and their parents. Parents' participation is observed occasionally in private schools when conferences are held or administrative decisions are to be communicated. In contrast, parents' participation is rarely observed in public schools.

\section{Students' Sport, Leisure Activities and Food Preferences}

Football, basketball, swimming, walking or running, volleyball, horseback riding and tennis are popular sports among Lebanese youth. Some dissimilarity had risen between these students related to gender and geographical areas. For e.g. in private urban schools boys like football, while girls like swimming.

Moreover, the favorite hobbies of the students differed by schools profile and geographical areas. Thus, almost all students in public and rural private schools have sedentary leisure activities such as watching television, videogames and surfing the Internet. Only students in urban private schools have leisure physical activities including football and basketball.

The students' favorite meals varied from types of schools. Thus, almost all students in private schools and public rural schools 
prefer homemade traditional Lebanese dishes unlike those in public urban schools, especially children and boys, who prefer fast food. All students listed mankoucheh, crescents and sandwiches "cheese, labneh, thyme, ham, chocolate" as snack options. Other less common snacks were reported differently upon regions such as: "chips" mainly by children in urban public schools, "chocolate" mainly by adolescents in rural schools. Note that the snacks listed in urban private schools are more diverse and students of these schools have special dietary behaviors. For example, adolescents in the Francophone school do not like eating at school and students in the Anglophone school were the only youth who eat granola bars, donuts, pretzels and yogurt.

Common beverages chosen by all students are water and juice. The juice is the favorite drink of children, especially boys, in private schools. More precisely, adolescents in the Anglophone urban private school have replaced soft drinks with lemonade and hot chocolate while students in the Francophone urban private school have substituted it with iced tea.

The favorite restaurants of Lebanese youth, especially for outing with friends, are mostly local or international chains of fast food (McDonald, Burger King, Apple Bee, KFC, Domino's Pizza, Big Mommy, etc.) where they eat cheese burgers, pizza, fries, chicken nuggets, fajitas, crispy chicken and Lebanese fast food sandwich "shawarma".

Only girls in private schools visit the "a la carte" restaurants when they are in family outing where they eat steak with vegetables, salads and grilled Lebanese dishes with rice. Besides, adolescents in urban private schools reported having hot chocolate and bagels with their friends in international coffee chains (Starbucks, Gloria Jeans Cafe's).

\section{Perception of Healthy Food, Healthy Lifestyle and Sources of Health and Nutrition Information}

All participants gave almost the same definition of healthy food "healthy food helps to maintain a good health and prevents from diseases", and of healthy lifestyle "healthy lifestyle is a state of physical and biological well-being achieved by eating healthy food, exercising regularly and absence of smoking".

Only a small number of students identified health problems within Lebanese youth and did not perceive themselves at risk to develop health problems in the future. These problems are weight problems, dental problems, sedentary lifestyle, anemia, malnutrition, smoking (cigarette, water pipe), and eating disorders. According to all students, these problems require awareness campaigns and preventive intervention in diverse environments including schools, clubs, and communities.

The main health and nutrition information trustful sources identified by the students are the family (father and cousins for the boys, mother especially for adolescent girls, older sister for children), the school, the beauty magazines, the American TV programs (Dr. Phill, Oprah, etc.), and their peers especially in private schools. Likewise, youth reported the impact of the body image advertised in all media channels on their lifestyle choices. Results from this study showed that youth in public schools and rural areas are more interested in health information than those in private schools and urban areas.

\section{Attitude Toward the "SNP"}

All students perceived that Lebanese youth will be favorable to the SNP and will support its development if the resources (human and financial) and the structures (socio-economical, cultural, political, religious and regional "rural, urban") are carefully considered and evaluated. "Lebanese youth will support an eventual SNP if it is well designed by experts or youth idols and taking into consideration the needs and attitudes of boys, girls, children and adolescents living in different social contexts. Maybe wealthy urban adolescent girls will be more ready to support the SNP than boys!!"

Moreover, students identified the necessity of youth active participation throughout the process of the SNP development in order to ensure their compliance with policy elements after implementation. Students also recognized the importance of role-modeling behaviors that may help boost youth' self-efficacy skills.

Adolescents, especially in private schools, believe that SNP cannot improve alone the youth lifestyle. It is essential to act in synergy in other environments (households, peers, neighbors and food stores) and on health determinants including knowledge, and socioeconomic, demographic and political factors.

All participants reported that SNP is likely to influence youth lifestyle if they perceived its benefits on their physical appearance and health, if other environments and communities support the SNP, and if the SNP is monitored regularly.

In spite of the diversity of participants' perceptions of the facilitating factors and the barriers associated to the eventual development of the SNP, the analysis showed specific youth perceptions to each school profile and social context (Table 2). The specificity of perceptions results from the difference in age, gender, socioeconomic status and environmental context between the respondents.

Complementary results in table 2 have been presented accordingly to the conceptual framework categories of variables to approach youth attitude toward the SNP at various levels of action. Appropriate youth extracts were selected and agreed to support the findings. 


\begin{tabular}{|c|c|c|c|c|c|}
\hline Schools & Variables & Individual Variables & Community Variables & Organizational Variables & $\begin{array}{c}\text { Other Variables } \\
\text { (Motivation, mobilization, } \\
\text { social conflict, knowledge...) }\end{array}$ \\
\hline \multirow{2}{*}{$\begin{array}{l}\text { Private } \\
(\mathrm{n}=24 \\
\text { youth) }\end{array}$} & $\begin{array}{l}\text { Facilitating } \\
\text { factors }\end{array}$ & $\begin{array}{l}\text { - Convince youth with argu- } \\
\text { ments on the physical, mental } \\
\text { \& biological well-being } \\
\text { - Tailored messages with } \\
\text { respect to age "children like } \\
\text { innovation \& originality"l } \\
\text { - Recognize adolescents } \\
\text { needs\& idols "Justin Bieper is } \\
\text { one of our idols"l } \\
\text { - Respect youth autonomy } \\
\text { - Getting youth to feel respon- } \\
\text { sible \& reproductive }\end{array}$ & $\begin{array}{l}\text {-Sharing responsibilities be- } \\
\text { tween parents \& youth } \\
\text { - Emphasize on the physical } \\
\text { activity part of the SNP } \\
\text { - Adapt the SNP to the Leba- } \\
\text { nese culture \& youth needs } \\
\text { - Presence of reinforcing com- } \\
\text { munities }{ }^{2} \\
\text { - Parental role modeling } \\
\text { "father and/or mother role } \\
\text { modeling"l } \\
\text { - Peer pressure }\end{array}$ & $\begin{array}{c}\text { - Ameliorate school food ser- } \\
\text { vices (quality, taste, variety)1 } \\
\text { - Increase time \& varieties of } \\
\text { physical activities } \\
\text { - Gain the school personnel } \\
\text { support } \\
\text { - Interactive communication } \\
\text { between young people "I } \\
\text { prefer to participate in school } \\
\text { activities given by other peers" }\end{array}$ & $\begin{array}{l}\text { - Banishing unhealthy food } \\
\text { from all environments "avail- } \\
\text { ability of sugar \& salty snacks is } \\
\text { attempting" } \\
\text {-Establishment of legislations } \\
\text { - Ensure youth motivation \& } \\
\text { mobilization (positive effect of } \\
\text { parents \& popular persons) }{ }^{1} \\
\text { - Regular follow-up } \\
\text { - Role of health professionals, } \\
\text { experts \& parents in increasing } \\
\text { youth knowledge }\end{array}$ \\
\hline & Barriers & $\begin{array}{l}\text {-Absence of youth perception } \\
\text { of health risk susceptibility \& } \\
\text { severity } \\
\text { - Heterogeneity in youth } \\
\text { perceptions with respect to age } \\
\text { \& gender }{ }^{1} \\
\text { - Girls obsession with body } \\
\text { image } \\
\text { - Youth resistance to comply } \\
\text { with the nutrition content of } \\
\text { the SNP more than the physi- } \\
\text { cal activity part }\end{array}$ & $\begin{array}{c}\text { - Discrepancies in youth } \\
\text { mentalities } \\
\text { - Peer pressure } \\
\text {-Difficulty to change acquired } \\
\text { patterns from familial environ- } \\
\text { ment }^{2} \\
\text { - Religion restrictions }{ }^{2}\end{array}$ & $\begin{array}{l}\text { - Lack of health education } \\
\text { - Lack of physical education in } \\
\text { public school } \\
\text { - Inappropriate scholar physi- } \\
\text { cal environment } \\
\text { - Accessibility \& availability of } \\
\text { unhealthy food }\end{array}$ & $\begin{array}{l}\text { - Lack of interest in health } \\
\text { information }{ }^{2} \\
\text { - Difficulty to motivate \& to } \\
\text { mobilize adolescents }\end{array}$ \\
\hline \multirow{2}{*}{$\begin{array}{l}\text { Public } \\
(\mathrm{n}=24 \\
\text { youth) }\end{array}$} & $\begin{array}{l}\text { Facilitating } \\
\text { factors }\end{array}$ & $\begin{array}{l}\text { - Increase youth perceptions } \\
\text { of SNP advantages on the } \\
\text { physical, mental \& biological } \\
\text { well-being }{ }^{2} \\
\text { - Using body image \& social } \\
\text { acceptance arguments }\end{array}$ & $\begin{array}{l}\text {-Ensure broad participation } \\
\text { among young people } \\
\text { - Parental \& social role mod- } \\
\text { eling } \\
\text { - Peer pressure (for girls) } \\
\text { - Presence of reinforcing } \\
\text { environments }\end{array}$ & $\begin{array}{l}\text { - Communicate SNP by using } \\
\text { conferences } 2 \text { and "talk shows } \\
\text { ఓ reportages"1 } \\
\text { - Active school health advisors } 2 \\
\text { - Intra scholar collaboration1 } \\
\text { - Use of strict regulations2 }\end{array}$ & $\begin{array}{l}\text { - Increasing youth knowledge } \\
\text { (role of schools \& parents) }^{1} \\
\text { - Social segmentation } \\
\text { - National mobilization }\end{array}$ \\
\hline & Barriers & $\begin{array}{l}\text { - Absence of perception of risk } \\
\text { susceptibility } \\
\text { - Polluted environment "the } \\
\text { Lebanese environment is pol- } \\
\text { luted \& not helpful for the SNP } \\
\text { development". } \\
\text { - Food insecurity }\end{array}$ & $\begin{array}{l}\text {-Difference between youth } \\
\text { perceptions with respect to } \\
\text { regional belonging } \\
\text { - Lack of youth enthusiasm \& } \\
\text { willingness to participate in } \\
\text { the SSH 1 } \\
\text { - Peer pressure (for boys) }\end{array}$ & $\begin{array}{l}\text { - Lack of scholar health } \\
\text { services }{ }^{1} \\
\text { - Irresponsible school person- } \\
\text { nel }{ }^{1} \\
\text { - Inappropriate school physical } \\
\text { environment }\end{array}$ & $\begin{array}{l}\text { - Diversity in social \& regional } \\
\text { structure } \\
\text { - Gender discrimination in } \\
\text { physical activity classes "we let } \\
\text { boys play more than girls"1 }\end{array}$ \\
\hline
\end{tabular}

$1=$ Urban schools; $2=$ Rural schools. Italic statements are youth extracts

Table 2: Perceptions of Youth Associated With an Eventual Development of School Nutrition Policy (SNP) in Lebanon. (n=48)

\section{Discussion}

There is substantial evidence indicating how formative research based on social marketing approach can result in more culturally appropriate and effective nutrition interventions in different social Lebanese contexts $[19,22,29,30]$. Although data on population level physical activity and eating behavior in Lebanon are limited in terms of temporal trends, this study showed that youth are very active, especially in private schools despite the increasing in leisure-time sedentary activities [31].

The findings of this study indicate that public schools are less interested in physical activity than private schools [20]. Barriers to implement nutrition and physical activity in public schools more than in private schools such as: lack of discipline, absence of collaboration between school and parents, poverty, and lack of human and financial resources [32]. Results from private schools highlight the importance of school leadership, professionalism and capacity building to facilitate SNP development especially in the diverse Lebanese contexts [32]. Besides the school profile and its built environment features, regional characteristics should be thoroughly considered $[15,19,20]$. For example, many factors listed in table 2 can reinforce school nutrition programs in urban regions including originality and innovations in ideas, parental and social influences, and use of national nutritional legislations [33]. In contrast, leadership of schools and government, receptive communities, and familiarity with traditional Lebanese food are essential facilitating factors in rural regions [31].

In particularly, extracts in table 2 showed that youth in private schools have wider perceptions on how SNP could be efficient. They ask to be more responsible and to respect their autonomy and needs. However, youth in public schools appears to be more passive but aware of their inappropriate school environment for SNP development. It was evident that youth in urban are more able to articulate their health perceptions, attitudes and needs than youth in rural area.

This study has demonstrated that youth's dietary and physical activity patterns are strongly influenced by characteristics of both 
physical and socioeconomic environments [8,14-15]. Time constraints, taste, advertising, nutrition promotion and education especially if delivered by their idols are the primary factors motivating their food behaviors and physical activity $[7,8,11,29]$.

Findings also identified youth', especially children', food related knowledge; preferences and consumption are related to parent's preferences, beliefs, and attitudes toward food [14,33]. Although parents, especially mothers, provide the strongest influence on children's health beliefs and behaviorism, they are not the only actor to model their lifestyle $[14,34,35]$. Children and adolescents alike are also influenced positively or negatively by what their peers eat and if they exercise [14, 35,36].

Youth think that health problems related to unhealthy lifestyle are long-term outcomes and still they are young and probably consider themselves impervious to them "it won't happen to me" [37,38]. However, students were able to clearly define healthy food and lifestyle but in practice their behaviors and food choices reflect that knowledge alone does not bring about change $[3,8,37]$. Other factors including peer acceptance and seeking social identity have greater influence resulting in less healthy food choices and sedentary lifestyle $[8,9,11,39]$. Another area of influence is advertising (TV, magazines, billboards, groceries) and it is evident as reported in this study that youth are influenced by advertising methods especially "images", such as the use of characters on packaging, the television food advertisements, the advertisements done by the popular local and international artists $[8,10,36,39,40]$. One young boy stated "I will do whatever Justin Bieper will tell me to do".

Today's youth live in a media-saturated environment $[10,41,42]$. Youth of this study reported that all of the mediated approaches (mass and social media) to nutrition and physical activity program deliver are likely to be important elements of the dissemination of the SNP [29,42]. Combinations of communication channels and mutually supportive and integrated strategies are likely to be more effective and need to be developed and evaluated systematically $[25,29,42,43]$. Hence, a tailored approach is important to use information elicited from youth to create a message based on their current beliefs, habits, attitudes, knowledge and social structure $[35,41,44]$. The results confirm that Lebanese youth should be segmented into groups with respect to age, gender, socioeconomic status, beliefs and regional belonging in order to receive efficient tailored messages. In particular, adolescents are not a monolithic group and should be segmented into sub-groups based on attitudes and lifestyles [9].

Consistent with other studies, compiled results of this research also reinforced the feasibility of cooperation between multidisciplinary and multi-sectorial active stakeholders to work and maintain the implementation of the SNP into community-based institutions such as schools $[25,26,30,45,46]$. Establishing sustained alliances between schools, families, communities, health professionals, media and food industries, and influential politicians or popular idols creates a more health-promoting environment in order to ensure the SNP acceptance by youth and its sustainability $[11,25]$.

Students perceived the everyday situations of Lebanese youth need to be studied more intensively; indicators are needed to follow up the developments towards healthy lifestyle goals [3,25]. Therefore, investigations on nutrition behavior of youth should depend on: 1) longitudinal perspectives (consider the time dimension in behavioral changes related to cultural and social changes); 2) nutrition competences of health communicators in promoting health; 3) housekeeping activities especially near single parents (time management, culinary competences); and 4) effects of information and communication for changing lifestyle [3,43].

It is worth considering how nutrition and public policies can affect dietary patterns, lifestyles and food economics [5,6,29]. The effect of nutrition policies, especially in schools, is to shift the demand curve by providing more information on nutrition relatedhealth effects, enjoyability of foods and ease of their preparation to youth and their communities [6,29].

Indeed, the potential impact of the SNP on ameliorating Lebanese youth nutrition knowledge, and behavior could be interesting especially if it is conducted continuously and evaluated regularly. A basic ideology is that of reciprocal determinism between environments and behaviors. For example, schools can shape, maintain and constraint students lifestyles but youth can also create and changer their environment if there is a will [6].

This study shares the limitation of other studies that require the support of applied research in order to plan, to implement and to monitor evidence-based programs such as the SNP [3]. Knowledge on Lebanese youth food behavior and previous health promotion researches are insufficient or marginal. This research was exploratory and intended to inspire thought rather than draw firm conclusions. The sample size may seem small but it is appropriate for qualitative studies [47].

Finally, the current study differs from past research on school nutrition policies in 3 respects: Firstly, we used an innovative integrated comprehensive conceptual framework evaluated by a panel of nutrition school policies experts in Quebec to ensure the internal and external validity of the research design and instrumentations. Secondly, we used a social marketing approach to study students' perceptions knowing that its objective is to change behavior not only communicating information. Thirdly, we explored youth perceptions to direct the SNP development during the pre-implementation phase rather than relying only on the perceptions and attitudes of the school personnel and parents after policy implementation.

\section{Implications for research and practice}

This study is a stepping-stone for future research to begin to understand the sensitivity of school profiles and network systems to varying youth perceptions and peer influence, and to further consider how to translate our disparate findings at an individual 
and aggregate level to inform school-based nutrition policies. Beside school nutrition intervention, there is a need for other environmental interventions and public policies such as on food stores and on urbanization to increase the use of walking and bicycling as a transport mode to schools [11,15,29].

\section{Conclusion}

It is important to integrate a comprehensive approach to explore youth perceptions of barriers and facilitators at different levels of influence, which complement and build upon each other, in order to thrive SNP development. The present study incorporates findings from behavioral economics, food marketing and psycho-sociology to propose insights into how youth, coming from different socio-economic contexts, perceive and make healthy lifestyle decisions. Recognizing that dietary and physical activity choices are determined by factors other than prices, income, and nutrition information broadens the array of strategies that could influence youth lifestyle choices. Hence, a thorough analysis of costs, benefits, and potential impacts would be needed before any strategy (e.g. SSH) could be considered as a policy option in different school profiles. Future studies should also consider a full economic evaluation that would focus on the overall tradeoffs between the cost of implementing the nutritional policies and the short- and long-term changes in food and physical activity behaviors, and their impact on youth health and lifestyle perceptions.

Further researches completed by the authors of this article will continue to complement current findings with regards to school personnel, parents and other Lebanese key stakeholders' perceptions of the SNP determinants (Hamadeh S, Marquis M, submitted data, 2016; Hamadeh S. oral communication, 2014\& 2015).

\section{Acknowledgements}

The authors gratefully acknowledge the students, the schools' personnel who participated and made this work possible. The authors declare that they have no competing interests.

\section{References}

1. Hamadeh S, ElZein H (2011) Prevalence and Etiology: Middle East and North Africa (MENA) Countries. In: Moreno AL, Pigeot I, Ahrens W. Epidemiology of Obesity in Children and Adolescents - Prevalence and Aetiology. Springer, New York, USA.

2. Zazpe I, Sánchez-Tainta A, Toledo E, Anchez-Villegas A, Martínez-González MÁ (2014) Dietary patterns and total mortality in a Mediterranean cohort: the SUN project. J Acad Nutr Diet 114: 37-47.

3. Oltersdorf U (2003) Impact of nutrition behaviour research on nutrition programmes and nutrition policy. Appetite 41: 239-44.

4. R-Just D, Mancino L, Wansink B (2007) Could Behavioral Economics Help Improve Diet Quality for Nutrition Assistance Program Participants? United States Department of Agriculture - Economic Research Service Report 43: 34.

5. Lenoir-Wijnkoop I, Dapoigny M, Dubois D, Van Ganse E, Gutierrez-Ibaulezea I, et al. (2011) Nutrition economics: Characterizing the economic and health impact of nutrition. BJN 105: 157-66.

6. Lenoir-Wijnkoop I, Jones PJ, Uauy R, Segal L, Milner J (2013) Nutrition economics: Food as an ally of public health. BJN 109: 777-784.

7. Hamadeh S, Marquis M (2008) Food motivation: Content analysis of Chatelaine women's magazine. J Nutr Food Sci 38: 52-60.

8. Warwick J, Mcilveen H, Strugnell Ch (1997) Food choices and the younger generation. J Consumer Stud Home Econ 21: 141-149.

9. Story M, Neumark-Sztainer D, French S (2002) Individual and environmental influences on adolescent eating behaviors. J Am Diet Assoc 102: S40-S51.

10. Arnas YA (2006) The effects of television food advertisement on children's food purchasing requests. Pediatr Int 48: 138-145.

11. French S, Story M, Jeffery RW (2001) Environmental influences on eating and physical activity. Annu Rev Public Health 22: 309-35.

12. Gittelsohn J, Kumar MB (2007) Preventing childhood obesity and diabetes: is it time to move out of the school? Pediatr Diabetes 8: 1-15.

13. Naja F, Hwalla N, Itani L, Karam S, Sibai A, Nasreddine L (2015) A western dietary pattern is associated with overweight and obesity in a national sample of Lebanese adolescents (13-19 years): a cross -sectional study. BJN 114: 1909-19.

14. Patrick H, Nicklas T (2005) A review of family and social determinants of children's eating patterns and diet quality. J Am Coll Nutr $24: 83-92$.

15. Caroll-Scott A, Gilstad-Hayden K, Rosenthal L, Eldahan A, McCaslin C, et al. (2015) Associations of Neighborhoods and School Socioeconomic and Social Contexts with BMI among Urban Preadolescent students. AJPH 105: 2496-502.

16. Afifi R, Yeretzian J, Rouhana A, Nehlawi M, Mack A (2009) Neighborhood influences on narghile smoking among youth in Beirut. Eur J Pub Health. 20 : 456-62.

17. Cvjetan B, Ulter J, Robinson E, Denny S (2014) The social environment of schools and adolescent nutrition: associations between the school nutrition climate and adolescents' eating behaviors and body mass index. J Sch Health 84: 677-82.

18. Sibai M, Nasreddine L, Mokdad AH, Adra N, Tabet M (2010) Nutrition transition and cardiovascular disease risk factors in Middle East and North Africa countries: reviewing the evidence. Ann Nutr Metab 57: 193-203.

19. Sibai M, Hwalla N, Adra N, Rahal B (2003) Prevalence and covariates of obesity in Lebanon: findings from the first epidemiological study. Obes Res 11: 135361.

20. Jabre P, Khater-Menassa B, Baddoura R, Awada H (2003) Overweight children in Beirut: Prevalence estimates and characteristics. Child Care Health Dev 31: 159-65.

21. Ministry of Education in Lebanon (2009) Strategy for school health in Lebanon-Report (in Arabic). Department of school health.

22. Young L, Anderson J, Beckstrom L, Bellows L, Johnson SL (2004) Using social marketing principles to guide the development of nutrition education initiative for preschool-aged children. J Nutr Educ Behav 36: 250-7.

23. Bastien R, Langevin L, LaRocque G, Renaud L (1994) Promouvoir la santé: Réflexions sur les théories et les pratiques. Marquis, Quebec, Canada.

24. Delisle H, Strychar I (2006) Obesity at adolescence: prevention is timely even in low income countries. UNSCN news. 3: 51-57. 
25. Désy M (2009) Lécole en santé: Recension des écrits. Santé Canada: Agence de la santé et des services sociaux de Montréal. (The Healthy School: literature review. Health Canada: Health and Social Services Agency of Montreal).

26. Glanz k, Rimer B, Viswanath K (2008) Health behavior and health education: theory, research and practice (4 $4^{\text {th }}$ edn). Jossey-Bass Publishers, San Francisco, USA.

27. Center for diseases control and prevention. Child and teen BMI calculator.

28. Paillé P, Mucchielli A (2008) Lanalyse qualitative en sciences humaines et sociales ( $2^{\text {nd }}$ edn). Armand Colin Publisher, Paris, France.

29. Gittelsohn J, Dyckman W, Tan ML, Boggs MK, Frick KD, et al. (2006) Development and implementation of a food store-based intervention to improve diet in the republic of the Marshall Islands. Health Promot Pract 7: 1-10.

30. World Health Organization (2008) School Policy framework: Implementation of the Global Strategy on Diet, Physical activity and Health.

31. Chakar H, Salameh P (2006) Adolescent obesity in Lebanese private schools. Eur J Pub Health 16:648-51.

32. Tamim H, Al-Sahab B, Akkary G, Ghanem M, Tamim N, et al. (2007) Cigarette and nargileh smoking practices among school students in Beirut, Lebanon. Am J Health Behav 31: 56-63.

33. Habib R, Hamdan M, AlSahab B, Tamim H, Mack A, et al. (2010) The influence of parent-child relationship on safety belt use among school children. Health Promot Int 25: 403-11.

34. Guenther P, Luick B (2015) Improved overall quality of diets reported by expanded food and nutrition education program participants in the mountain region. J Nutr Educ Behav 47: 421-6.

35. Heidelberger L, Smith Ch (2015) The food environment through the camera lenses of 9 to 13 years olds living in urban, low-income, Midwestern households: A photovoice project. J Nutr Educ Behav 47: 437-45.

36. McGuffin L, Price R, McCaffrey T, Hall G, Lobo A, et al. (2015) Parent and child perspectives on family out-of-home eating: a qualitative analysis. Public Health Nutr 18: 100-11.

37. Yeretzian J, Afifi R (2009) "It won't happen to me": the knowledge-attitude nexus in adolescent smoking. J Public Health 31 : $354-9$.

38. Wilson A, Renzalo A (2015) Intergenerational differences in acculturation experiences, food beliefs and perceived health risks among refugees from the horn of Africa in Melbourne, Australia. Public Health Nutr 18: 176-88

39. Cruwys T, Bevelander K, Hermans R (2015) Social modeling of eating: a review of when and why social influence affects food intake and choice. Appetite 86: 3-18.

40. Reger B, Wootan MG, Booth-Butterfield S (1999) Using mass media to promote healthy eating: A community-based demonstration project. Prev. Med 29: 414-21.

41. Brinberg D, Axelson ML, Price S (2000) Changing food knowledge, food choice, and dietary fiber consumption by using tailored messages. Appetite 35: 35-43. 42. Marshall AL, Owen N, Bauman AE (2004) Mediated approaches for influencing physical activity: update of the evidence on mass media, print, telephone and website delivery of interventions. J Sci Med Sport 7: 74-80.

43. World Health Organization (2007) Planning for effective communication strategies to improve national nutrition programmes. Regional Office for the Eastern Mediterranean.

44. Holt NL, Neely KC, Newton AS, Knight CJ, Rasquinha A, et al. (2015) Families' perceptions of and experiences related to a pediatric weight management intervention: a qualitative study. J Nutr Educ Behav 47: 427-31.

45. Narhinen M, Nissimen A, Puska P (1999) Healthier choices in a supermarket. The municipal food control can promote health. BFJ 101: 99-107.

46. Richard L, Gauvin L, Raine K (2011) Ecological Model Revisited: Their uses and evaluation in health promotion over two decades. Annu Rev Public Health 32: 307-26.

47. Sarantakos S (2005) Social Research ( $3^{\text {rd }}$ edn). Palgrave Macmillan Publisher, Melbourne, Australia.

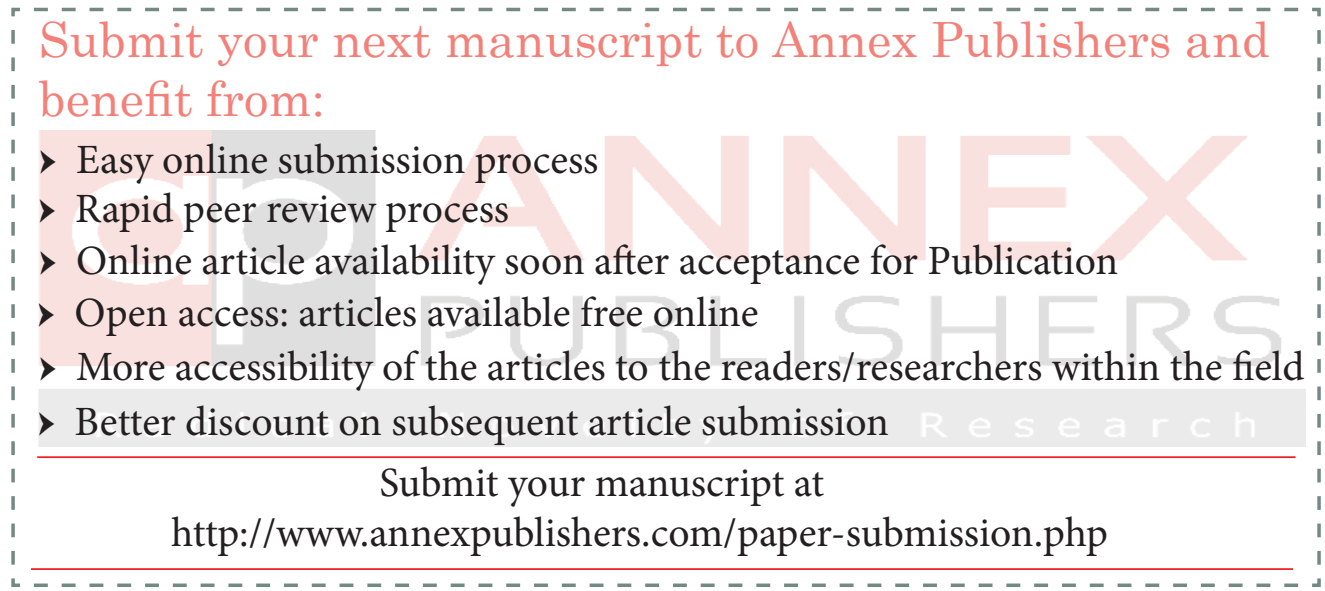

